\title{
Extremal Solutions of Boundary Value Problems Using Fixed Point Theorems
}

\author{
V. C. Borkar \\ Department of Mathematics, Yeshwant Mahavidyalaya,Nanded 431605, INDIA
}

\begin{abstract}
Existence of extremal fixed points of A + B is obtained in ordered Banach spaces. Some applications to two- point boundary value problems in ordinary differential equations are discussed.
\end{abstract}

\section{AMS (MOS) 2000 Subject classifications: 34 A 40, 34 B15.}

\section{INTRODUCTION}

Krasnoselskii [2] proved the existence of fixed points of $A+B$ in closed convex Banach spaces while many mathematician had obtained its extremal fixed points in ordered Banach spaces. Here we generalize some results of $[1$.

Let $X$ be a Banach space and $\mathrm{K}$ a cone in $\mathrm{X}$. Let $\leq$ be a partial ordering defined by Ki.e. for $x, y$ in $\mathrm{X}, x \leq \mathrm{y}$ if $\mathrm{y}-x \in \mathrm{K}$. A cone $\mathrm{K}$ is said to be regular, if every increasing and bounded in order sequence has a limit and normal if there exists $\mathrm{N}>0$ such that $0 \leq x \leq \mathrm{y}$ implies $\|x\| \leq \mathrm{N}\|\mathrm{y}\|$. The details about cone and their properties may be found in [1].

Let $x_{0}, \mathrm{y}_{0} \in \mathrm{X}$ with $x_{0} \leq \mathrm{y}_{0}$, the set $\left[x_{0}, \mathrm{y}_{0}\right]=\left\{x \in \mathrm{X}: x_{0} \leq x \leq \mathrm{y}_{0}\right\}$ is called order interval in $\mathrm{X}$.

A mapping $\mathrm{T}: \mathrm{D} \subset \mathrm{X} \rightarrow \mathrm{X}$ is said to be increasing if $\mathrm{X}_{1} \leq \mathrm{x}_{2}$ implies

$\mathrm{T} \mathrm{x}_{1} \leq \mathrm{T} \mathrm{x}_{2}$. T is said to be a nonlinear contraction if there exist a lower semi continuous real function $\phi$ with $\phi(\mathrm{r})<\mathrm{r}, \quad \mathrm{r}>$ 0 satisfying

$\|\mathrm{T} x-\mathrm{Ty}\| \leq \phi(\|x-\mathrm{y}\|)$, for all $x, \mathrm{y}$ in $\mathrm{D}$.

A mapping $\mathrm{T}$ is said to be condensing if $\gamma(\mathrm{T}(\mathrm{S}))<\gamma(\mathrm{S})$ where $\mathrm{S} \subset \mathrm{D}$ and $\gamma$ is Kuratowskii's measure of noncompactness .

It is evident that if $\mathrm{T}$ is completely continuous then it is condensing.

\section{FIXED POINT THEOREMS.}

Theorem 2.1: Let $\mathrm{x}_{0}, \mathrm{y}_{0} \in \mathrm{X}, \mathrm{x}_{0}<\mathrm{y}_{0}$ and $\mathrm{A}, \mathrm{B}:\left[\mathrm{x}_{0}, \mathrm{y}_{0}\right] \rightarrow \mathrm{X}$ satisfy the following conditions:

$\left(\mathrm{H}_{1}\right)$ A is a nonlinear contraction,

$\left(\mathrm{H}_{2}\right) \quad \mathrm{Ax}+\mathrm{By} \in\left[\mathrm{x}_{0}, \mathrm{y}_{0}\right]$ for $\mathrm{x}, \mathrm{y} \in\left[\mathrm{x}_{0}, \mathrm{y}_{0}\right]$

$\left(\mathrm{H}_{3}\right) \quad(\mathrm{I}-\mathrm{A})^{-1} \mathrm{~B}$ is increasing where I denote an identity operator

$\left(\mathrm{H}_{4}\right) \quad B$ is semi continuous i.e. $\mathrm{x}_{\mathrm{n}} \rightarrow \mathrm{x}$ strongly

$$
\Rightarrow \mathrm{Bx}_{\mathrm{n}} \rightarrow \mathrm{Bx} \text { weakly. }
$$

Suppose that the cone $\mathrm{K}$ in the Banach space $\mathrm{X}$ is regular. Then the mapping $\mathrm{A}+\mathrm{B}$ has maximal and minimal fixed points in $\left[\mathrm{x}_{0}, \mathrm{y}_{0}\right]$.

Proof: Assume $T=(I-A)^{-1} B$, the existence of $T$ is guaranteed by hypothesis $\left(\mathrm{H}_{1}\right)$. Claim that $\mathrm{T}$ maps $\left[\mathrm{x}_{0}, \mathrm{y}_{0}\right]$ into itself. For fixed $\mathrm{y} \in\left[\mathrm{x}_{0}, \mathrm{y}_{0}\right]$ define a mapping $\mathrm{A}_{\mathrm{y}}$ on $\left[\mathrm{x}_{0}, \mathrm{y}_{0}\right]$ by

$$
\mathrm{A}_{\mathrm{y}}(\mathrm{x})=\mathrm{Ax}+\mathrm{By}
$$

where $\mathrm{x} \in\left[\mathrm{x}_{0}, \mathrm{y}_{0}\right]$. Hypothesis $\left(\mathrm{H}_{2}\right)$ implies that $\mathrm{A}_{\mathrm{y}}$ maps $\left[\mathrm{x}_{0}, \mathrm{y}_{0}\right]$ into itself moreover for $\mathrm{x}_{1}, \mathrm{x}_{2} \in\left[\mathrm{x}_{0}, \mathrm{y}_{0}\right]$

$$
\left\|\mathrm{A}_{\mathrm{y}}\left(\mathrm{x}_{1}\right)-\mathrm{A}_{\mathrm{y}}\left(\mathrm{x}_{2}\right)\right\| \leq \phi\left(\left\|\mathrm{x}_{1}-\mathrm{x}_{2}\right\|\right)
$$

and hence $A_{y}$ is a nonlinear contraction. Therefore $A_{y}$ has a unique fixed point $y^{\prime} \in\left[x_{0}, y_{0}\right]$ such that $A_{y}\left(y^{\prime}\right)=y^{\prime}$. Now for $\mathrm{x} \in\left[\mathrm{x}_{0}, \mathrm{y}_{0}\right]$,

$\mathrm{Tx}=\mathrm{y} \quad \Rightarrow \mathrm{Ay}+\mathrm{Bx}=\mathrm{y} \quad \Rightarrow \mathrm{A}_{\mathrm{x}}(\mathrm{y})=\mathrm{y}$

But $\mathrm{A}_{\mathrm{x}}$ has unique fixed point in $\left[\mathrm{x}_{0}, \mathrm{y}_{0}\right]$ and hence $\mathrm{T} x \in\left[\mathrm{x}_{0}, \mathrm{y}_{0}\right]$. Therefore $\mathrm{T}$ maps $\left[\mathrm{x}_{0}, \mathrm{y}_{0}\right]$ into itself.

Now consider the sequences $\left\{\mathrm{x}_{\mathrm{n}}\right\}$ and $\left\{\mathrm{y}_{\mathrm{n}}\right\}$ defined by

Hypothesis $\left(\mathrm{H}_{3}\right)$ implies that

$$
\mathrm{x}_{\mathrm{n}+1}=\mathrm{Tx}_{\mathrm{n}} \text { and } \mathrm{y}_{\mathrm{n}+1}=\mathrm{Ty}_{\mathrm{n}}
$$

$$
\mathrm{x}_{0} \leq \mathrm{x}_{1} \leq \mathrm{x}_{2} \leq \ldots . \leq \mathrm{x}_{\mathrm{n}} \leq \ldots \leq \mathrm{y}_{\mathrm{n}} \leq \ldots \ldots \leq \mathrm{y}_{1} \leq \mathrm{y}_{0}
$$

Since $\mathrm{K}$ is regular and sequences $\left\{\mathrm{x}_{\mathrm{n}}\right\}$ and $\left\{\mathrm{y}_{\mathrm{n}}\right\}$ are bounded in order, these sequences converge to $x^{*}$ and $\mathrm{y}^{*}$ respectively. Hypothesis $\left(\mathrm{H}_{4}\right)$ implies that $\mathrm{T}$ is semi continuous and so $\mathrm{Tx}^{*}=\mathrm{x}^{*}$ and $\mathrm{Ty}^{*}=\mathrm{y}^{*}$. The fixed points of $\mathrm{T}$ are also fixed points of $\mathrm{A}$ $+\mathrm{B}$. Therefore $\mathrm{x}^{*}$ and $\mathrm{y}^{*}$ are fixed points of $\mathrm{A}+\mathrm{B}$. 
IOSR Journal of Engineering

May. 2012, Vol. 2(5) pp: 1196-1199

If $x$ is any fixed point of $A+B$ then $x_{0} \leq x \leq y_{0}$. Since $T$ is increasing, $x_{1} \leq x \leq y_{1}$, and by induction $x_{n} \leq x \leq y_{n}$ for $n=$ $0,1,2,3 \ldots$ Taking the limits, we obtain $x^{*} \leq x \leq y^{*}$. Thus $x^{*}$ and $y^{*}$ are minimal and maximal fixed points of $\mathrm{A}+\mathrm{B}$. This completes the proof.

Corollary 2.1: Let the conditions of Theorem 2.1 be satisfied. Suppose $A+B$ has only one fixed point $x$ in $\left[\mathrm{x}_{0}, \mathrm{y}_{0}\right]$. Then for any $\mathrm{u}_{0} \in\left[\mathrm{x}_{0}, \mathrm{y}_{0}\right]$, the sequence

$$
u_{n+1}=A u_{n+1}+B u_{n}
$$

converges to $x$. i.e. $\left\|u_{n}-x\right\| \rightarrow 0 \quad(n \rightarrow \infty)$.

Proof: Define a mapping $\mathrm{T}$ on $\left[\mathrm{x}_{0}, \mathrm{y}_{0}\right]$ as in Theorem 2.1. Then the sequence (5) can be obtained as the successive iterates $\mathrm{u}_{\mathrm{n}+1}=\mathrm{Tu}_{\mathrm{n}}$.

Since $\mathrm{x}_{0} \leq \mathrm{u}_{0} \leq \mathrm{y}_{0}$ and $\mathrm{T}$ is increasing, $\mathrm{x}_{\mathrm{n}} \leq \mathrm{u}_{\mathrm{n}} \leq \mathrm{y}_{\mathrm{n}}$. By hypothesis, $\mathrm{x}$ is the only fixed point of $\mathrm{T}$ and hence $\mathrm{x}^{*}=\mathrm{x}=\mathrm{y}^{*}$ where $x^{*}$ and $y^{*}$ are limits of sequences $\left\{\mathrm{Tx}_{\mathrm{n}}\right\}$ and $\left\{\mathrm{Ty}_{\mathrm{n}}\right\}$. Cone $\mathrm{K}$ is regular implies that $\mathrm{K}$ is normal. So by normality of cone and Theorem 2.1, it follows that $\mathrm{u}_{\mathrm{n}} \rightarrow \mathrm{x}$.

Theorem 2.2: Let the conditions $\left(\mathrm{H}_{1}\right)$ and $\left(\mathrm{H}_{2}\right)$ of Theorem 2.1 be satisfied. If $B$ is completely continuous and $\mathrm{K}$ is normal then $\mathrm{A}+\mathrm{B}$ has a fixed point in $\left[\mathrm{x}_{0}, \mathrm{y}_{0}\right]$.

Proof: Define a mapping $\mathrm{T}$ as in Theorem 2.1. Therefore $\mathrm{T}$ maps $\quad\left[\mathrm{x}_{0}, \mathrm{y}_{0}\right]$ into itself. Since $(\mathrm{I}-\mathrm{A})^{-1}$ is continuous and B is completely continuous, $\mathrm{T}$ is also completely continuous. Moreover $\mathrm{K}$ is normal and hence order interval $\left[\mathrm{x}_{0}, \mathrm{y}_{0}\right]$ is closed convex and bounded. Existence of fixed point of T is now guaranteed by Schauder's theorem. Hence A $+\mathrm{B}$ has a fixed point.

Theorem 2.3: Assume conditions $\left(\mathrm{H}_{1}\right)-\left(\mathrm{H}_{3}\right)$ of theorem 2.1. If $\mathrm{B}$ is condensing and $\mathrm{K}$ is normal then $\mathrm{A}+\mathrm{B}$ has a fixed point.

Proof: Define a mapping $T$ as in Theorem 2.1. For fixed $u_{0} \in\left[x_{0}, y_{0}\right]$ define a sequence $\left\{u_{n}\right\}$ by $u_{n+1}=T u_{n}$. Let $S=\left\{u_{0}, u_{1}\right.$, $\left.\mathrm{u}_{2} \ldots\right\}$

$\therefore \quad \mathrm{S}=\mathrm{T}(\mathrm{S}) \cup\left\{\mathrm{u}_{0}\right\}$.

Since $(\mathrm{I}-\mathrm{A})^{-1}$ is continuous and $\mathrm{B}$ is condensing, $\mathrm{T}$ is also condensing.

Hence $\gamma(\mathrm{S})=\gamma(\mathrm{T}(\mathrm{S}))<\gamma(\mathrm{S})$. Therefore $\gamma(\mathrm{S})=0$. This implies that $\mathrm{S}$ is relatively compact. Hence there exists a subsequence \{ $\mathrm{u}_{\mathrm{n}_{\mathrm{k}}}$ \}of $\left\{\mathrm{u}_{\mathrm{n}}\right\}$ such that $\mathrm{u}_{\mathrm{n}_{\mathrm{k}}} \rightarrow \mathrm{x}^{*}$. But $\mathrm{K}$ is normal and so $\mathrm{u}_{\mathrm{n}} \rightarrow \mathrm{x}^{*}$. Taking limits $\mathrm{n} \rightarrow \infty$ in $\mathrm{u}_{\mathrm{n}}=\mathrm{Tu}_{\mathrm{n}-1}$, we get $\mathrm{x}^{*}=\mathrm{Tx}^{*}$ since $\mathrm{T}$ is continuous. Hence $\mathrm{x}^{*}$ is a desired fixed point of $\mathrm{A}+\mathrm{B}$.

Theorem 2.4: Assume conditions $\left(\mathrm{H}_{1}\right)-\left(\mathrm{H}_{4}\right)$ of Theorem 2.1. If $\mathrm{B}$ is condensing and $\mathrm{K}$ is normal then $\mathrm{A}+\mathrm{B}$ has minimal and maximal fixed points.

Proof: Define a mapping $T$ as in the proof of Theorem 2.1. Then the sequences $\left\{x_{n}\right\}$ and $\left\{y_{n}\right\}$ defined by (3) converge respectively to $x^{*}$ and $y^{*}$. It is obvious that $x^{*} \leq y^{*}$ and $x^{*}, y^{*}$ are fixed points of $T$. By similar procedure as expressed in Theorem 2.1, it can be proved that $\mathrm{x}^{*}$ and $\mathrm{y}^{*}$ are minimal and maximal fixed points of $\mathrm{A}+\mathrm{B}$.

Corollary 2.2: Let the condition of Theorem 2.4 be satisfied. Suppose $A+B$ has only one fixed point $x \in\left[x_{0}, y_{0}\right]$. Then for any $\mathrm{u}_{0} \in\left[\mathrm{x}_{0}, \mathrm{y}_{0}\right]$ the sequence of iterates defined by (5) converges to $\mathrm{x}$. i.e. $\left\|\mathrm{u}_{\mathrm{n}} \mathrm{x}\right\| \rightarrow 0$ as $(\mathrm{n} \rightarrow \infty)$.

The proof of this corollary is similar to that of corollary 2.1 .

Remark-1: Consider the condition

$\left(\mathbf{H}_{5}\right)$ : A is linear and $A^{k}$, for some $\mathrm{k} \in \mathrm{N}$, is nonlinear contraction on $\left[\mathrm{x}_{0}, \mathrm{y}_{0}\right]$.

If $\mathrm{A}_{\mathrm{y}}$ is defined by (2) then for any $\mathrm{x} \in\left[\mathrm{x}_{0}, \mathrm{y}_{0}\right]$ using linearity of $\mathrm{A}$, it follows that

$$
A_{y}^{k}(\mathrm{x})=A^{k} \mathrm{x}+\left(\mathrm{I}+\mathrm{A}+\mathrm{A}^{2}+\ldots+\mathrm{A}^{\mathrm{k}-1}\right) \mathrm{By} \text {. }
$$

Thus for $\mathrm{x}_{1}, \mathrm{x}_{2} \in\left[\mathrm{x}_{0}, \mathrm{y}_{0}\right]$,

$$
\left\|A_{y}^{k}\left(\mathrm{x}_{1}\right)-A_{y}^{k}\left(\mathrm{x}_{2}\right)\right\| \leq \phi\left(\left\|\mathrm{x}_{1}-\mathrm{x}_{2}\right\|\right)
$$

which shows that $A_{y}^{k}$ is a nonlinear contraction and hence $\mathrm{A}_{\mathrm{y}}$ has a unique fixed point. This guarantees the existence of mapping $\mathrm{T}$ as defined in the proof of Theorem 2.1. The definition of $\mathrm{A}_{\mathrm{y}}$ and $\mathrm{T}$ shows that $\mathrm{T}$ maps $\quad\left[\mathrm{x}_{0}, \mathrm{y}_{0}\right]$ into itself. Thus Theorem 2.1 holds even if the condition $\left(\mathrm{H}_{1}\right)$ is replaced by $\left(\mathrm{H}_{5}\right)$.

Remark 2: Theorem 2.1.1 of [2] appears as a special case of Theorem 2.1, which may be obtained by putting A $\equiv \theta$. 
IOSR Journal of Engineering

May. 2012, Vol. 2(5) pp: 1196-1199

Remark 3: The condition $\left(\mathrm{H}_{3}\right)$ had been imposed in the Theorem 3 of [3]. This condition can be excluded to obtain the result of Theorem 3 of [3] as seen from Theorem 2.2. Our approach to prove the Theorem is quite simple and different from that of [3].

Remark 4: Corollary 2.1.1 of [2] is a special case of Corollaries 2.1 and 2.2.

Remark 5: Theorem 2.2 holds even if the condition (H1) is replaced by (H5).

\section{APPLICATIONS}

Let $X=C[I, R]$ be the set of continuous real valued function defined on $I=[0,1]$ with supremum norm and $K=\{x \in X: x(t)$ $\geq 0,0 \leq t \leq 1\}$. Then $\mathrm{X}$ is a Banach space and $\mathrm{K}$ is a cone in $\mathrm{X}$. Moreover $\mathrm{K}$ is normal and regular. Consider the two-point boundary value problem of ordinary differential equation

$$
\begin{aligned}
& -\mathrm{x}^{\prime \prime}=\lambda \mathrm{f}(\mathrm{t}, \mathrm{x})+\mu \mathrm{g}(\mathrm{t}, \mathrm{x}) \\
& \mathrm{x}(0)=0=\mathrm{x}(1)
\end{aligned}
$$

where $\lambda, \mu$ are parameters and $\mathrm{f}, \mathrm{g}: \mathrm{IxX} \rightarrow \mathrm{X}$. The functions $\mathrm{u}$ and $\mathrm{v}$, in $\mathrm{C}^{(2)}[\mathrm{I}, \mathrm{R}]$ are said to be respectively lower and upper solutions of (6) if

$$
-\mathrm{u}^{\prime \prime}(\mathrm{t}) \geq \lambda \mathrm{f}(\mathrm{t}, \mathrm{u}(\mathrm{t}))+\mu \mathrm{g}(\mathrm{t}, \mathrm{u}(\mathrm{t}))
$$

and

$$
-\mathrm{v}^{\prime \prime}(\mathrm{t}) \leq \lambda \mathrm{f}(\mathrm{t}, \mathrm{u}(\mathrm{t}))+\mu \mathrm{g}(\mathrm{t}, \mathrm{u}(\mathrm{t}))
$$

We need the following assumptions:

$\left(\mathrm{A}_{1}\right) \mathrm{f}(\mathrm{t}, \mathrm{x})$ satisfies the Lipschitz condition in $\mathrm{x}$ with Lipschitz constant $\mathrm{L}$ i.e. there is a constant $\mathrm{L}>0$ such that

$$
\left|f\left(t, x_{1}\right)-f\left(t, x_{2}\right)\right| \leq L\left|x_{1}-x_{2}\right| \text {. }
$$

$\left(\mathrm{A}_{2}\right) \mathrm{g}(\mathrm{t}, \mathrm{x})$ is continuous on $0 \leq \mathrm{t} \leq 1$.

$\left(\mathrm{A}_{3}\right) \quad \mathrm{f}(\mathrm{t}, \mathrm{x})$ and $\mathrm{g}(\mathrm{t}, \mathrm{x})$ are increasing with respect to $\mathrm{x}$ i.e. for $0 \leq \mathrm{t} \leq 1,0 \leq \mathrm{x}_{1} \leq \mathrm{x}_{2}$.

and

$$
\begin{aligned}
& \mathrm{f}\left(\mathrm{t}, \mathrm{x}_{1}\right) \leq \mathrm{f}\left(\mathrm{t}, \mathrm{x}_{2}\right) \\
& \mathrm{g}\left(\mathrm{t}, \mathrm{x}_{1}\right) \leq \mathrm{g}\left(\mathrm{t}, \mathrm{x}_{2}\right) .
\end{aligned}
$$

It is obvious that $x_{\lambda, \mu}(t) \equiv 0$ is a trivial solution of problem (6) - (7) for any values of $\lambda$ and $\mu$.

Theorem 3.1: Assume $\left(A_{1}\right)-\left(A_{3}\right)$. Suppose that the function $u$ and $v$ are respectively the lower and upper solutions of equation (6). Further if $\lambda \mathrm{L}<8$, then the equations (6) - (7) have minimal and maximal solutions in [u, v].

Proof: It is well known that the solution of problem (6) - (7) is equivalent to the solution of integral equation

$$
x(t)=\int_{0}^{1} G(t, s)[\lambda f(s, x(s))+\mu g(s, x(s))] d s
$$

where $\mathrm{G}(\mathrm{t}, \mathrm{s})$ is the Green's function of differential operator - $\mathrm{x}^{\prime \prime}$

with respect to boundary conditions $\mathrm{x}(0)=0=\mathrm{x}(1)$ given by

$$
G(t, s)= \begin{cases}t(1-s) & \text { for } 0 \leq t \leq s \leq 1 \\ s(1-t) & \text { for } 0 \leq s \leq t \leq 1\end{cases}
$$

It is easy to show that

$$
\int_{0}^{1} G(t, s) d s=\frac{t(1-t)}{2} \leq \frac{1}{8} .
$$

Define

$$
\begin{aligned}
\operatorname{Ax}(\mathrm{t}) & =\lambda \int_{0}^{1} G(t, s) f(s, x(s)) d s \\
\text { and } \quad \operatorname{Bx}(\mathrm{t}) & =\mu \int_{0}^{1} G(t, s) g(s, x(s)) d s
\end{aligned}
$$

For any $\mathrm{x}, \mathrm{y}$ in $[\mathrm{u}, \mathrm{v}]$;

ISSN: 2250-3021 
IOSR Journal of Engineering

May. 2012, Vol. 2(5) pp: 1196-1199

$$
\begin{aligned}
\|\mathrm{Ax}-\mathrm{Ay}\| & =\sup _{\mathrm{t} \in \mathrm{I}}|\mathrm{Ax}(\mathrm{t})-\mathrm{Ay}(\mathrm{t})|, \\
& \leq \sup _{\mathrm{t} \in \mathrm{I}} \lambda \int_{0}^{1} G(t, s)|f(\mathrm{~s}, \mathrm{x}(\mathrm{s}))-\mathrm{f}(\mathrm{s}, \mathrm{y}(\mathrm{s}))| \mathrm{ds} \\
& \leq \sup _{\mathrm{t} \in \mathrm{I}} \lambda \mathrm{L} \int_{o}^{1} G(t, s)|\mathrm{x}(\mathrm{s})-\mathrm{y}(\mathrm{s})| \mathrm{ds} \\
& \leq \frac{\lambda L}{8}\|\mathrm{x}-\mathrm{y}\|
\end{aligned}
$$

Since $\lambda \mathrm{L}<8$, A becomes a contraction mapping on $[\mathrm{u}, \mathrm{v}]$ and so $\quad(\mathrm{I}-\mathrm{A})^{-1}$ exist. Hypothesis $\left(\mathrm{A}_{3}\right)$ implies that $(\mathrm{I}-\mathrm{A})^{-}$ ${ }^{1} \mathrm{~B}$ is increasing, $\left(\mathrm{A}_{2}\right)$ implies that $\mathrm{B}$ is completely continuous and hence $\mathrm{B}$ is condensing. Applying the theory of differential inequality to (8) and (9) we see that

$$
\begin{aligned}
\mathrm{u}(\mathrm{t}) & \leq \lambda \int_{0}^{1} \mathrm{G}(\mathrm{t}, \mathrm{s}) \mathrm{f}(\mathrm{s}, \mathrm{u}(\mathrm{s})) \mathrm{ds}+\mu \int_{0}^{1} \mathrm{G}(\mathrm{t}, \mathrm{s}) \mathrm{g}(\mathrm{s}, \mathrm{u}(\mathrm{s})) \mathrm{ds} \\
& \leq \lambda \int_{0}^{1} \mathrm{G}(\mathrm{t}, \mathrm{s}) \mathrm{f}(\mathrm{s}, \mathrm{x}(\mathrm{s})) \mathrm{ds}+\mu \int_{0}^{1} \mathrm{G}(\mathrm{t}, \mathrm{s}) \mathrm{g}(\mathrm{s}, \mathrm{y}(\mathrm{s})) \mathrm{d} \mathrm{s} \\
& =\mathrm{Ax}(\mathrm{t})+\mathrm{By}(\mathrm{t}) \\
& \leq \lambda \int_{0}^{1} \mathrm{G}(\mathrm{t}, \mathrm{s}) \mathrm{f}\left(\mathrm{s}, \mathrm{v}(\mathrm{s}) \mathrm{ds}+\mu \int_{0}^{1} \mathrm{G}(\mathrm{t}, \mathrm{s}) \mathrm{g}(\mathrm{s}, \mathrm{v}(\mathrm{s})) \mathrm{ds}\right. \\
\leq & \mathrm{v}(\mathrm{t})
\end{aligned}
$$

where $\mathrm{x}, \mathrm{y}$ are in $[\mathrm{u}, \mathrm{v}]$. Therefore A + B maps $[\mathrm{u}, \mathrm{v}]$ into itself. Theorem 2.4 asserts that $\mathrm{A}+\mathrm{B}$ has minimal and maximal fixed points in $[u, v]$ which are desired solutions of equations (6) - (7).

\section{REFERENCES}

1. Lakshmikantham V. and Dajun Guo; Nonlinear Problems in Abstract Cones; Academic Press INC.1988

2. Smart, D. R; Fixed point theorems, Cambridge University Press (1974), (page 31).

3. V.C. Borkar and S T Patil,: Existence and Uniqueness of Solutions in order Banach Spaces, Journal of Pure and Applied Mathematica Sciences Vol. LXI, No 1-2(X)March 2005 P.53-59

4. V.C Borkar. and S.T Patil.: Class of mixed Monotone operators and its application to operator equations. Bull of Pure \& Applied Sciences 22 E (1) (2003) 179-187. 